\title{
The Reliability Design \\ and Its Direct Effect on the Energy Efficiency
}

Seong-woo Woo, Jungwan Park, Jongyun Yoon and HongGyu Jeon

Additional information is available at the end of the chapter

http://dx.doi.org/10.5772/48790

\section{Introduction}

Reliability refers to the ability of system or component to perform a required function under stated environmental and operational conditions for a specified period of time. Traditionally, the reliability over the product life can be illustrated by a bathtub curve that has three regions: a decreasing rate of failure, a constant rate of failure, and an increasing rate of failure, as shown in Figure 1(a). As the reliability of a product (or part) improves, failure of the part becomes less frequent in the field. The bathtub curve may change into a straight line with the slope angle $\beta$. In a straight line there are two variables to be measured: product life $L_{в}$ (or mean time between failures) and failure rate $\lambda$, as shown in Eq. (1):

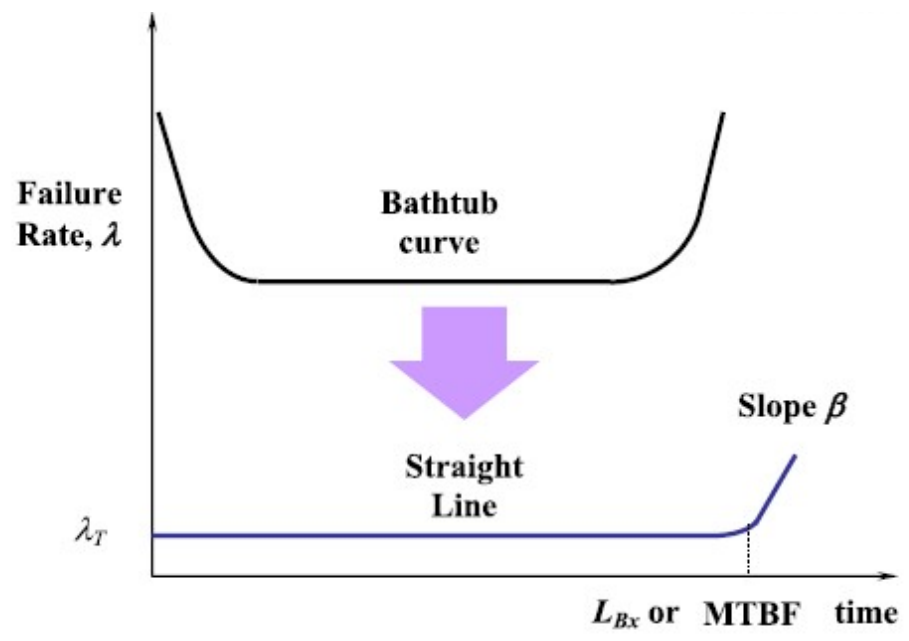

(a) The bathtub curve and straight line with slope $\beta$ 


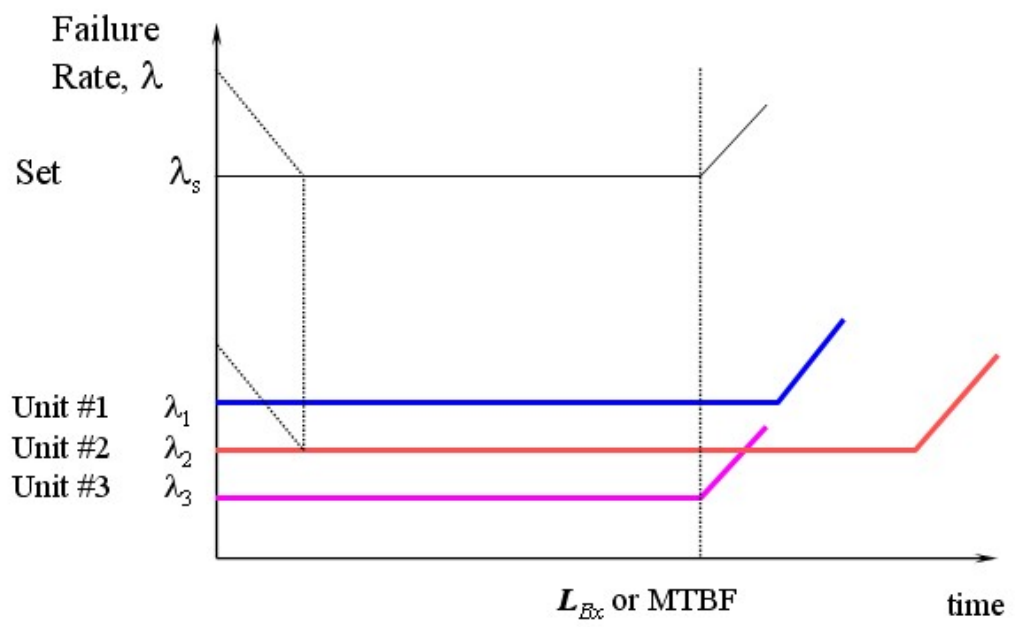

(b) System life and failure rate consisting of unit \#1, unit \#2 and unit \#3

Figure 1. System life and failure rate

$$
\mathrm{R}\left(\mathrm{L}_{\mathrm{B}}\right)=e^{-\lambda L_{B}} \cong 1-\lambda L_{B}
$$

We can thus establish the reliability growth plan of parts with a constant failure rate.

A company generally designs its new products to (1) minimize initial failures, (2) reduce random failures during the expected product working period, and (3) lengthen product life. Such aims are met through the use of robust design techniques, including statistical design of experiment (SDE) and the Taguchi methods [1]. The Taguchi methods describe the robustness of a system for evaluation and design improvement, which is also known as quality engineering [2-3] or robust engineering [4]. Robust design processes include concept design, parameter design, and tolerance design [5]. Taguchi's robust design methods place a design in an optimum position where random "noise" does not cause failure, which then and helps in determining the proper design parameters [6].

However, for a simple mechanical structure, the Taguchi methods' robust design processes need to consider a large number of design parameters. They also have difficulty in predicting the product life, $L в$ (or MTBF).

In this study we present a new method for the reliability design of mechanical systems. This new method takes into account the fact that products with missing or improper design parameters can result in recalls and loss of brand name value. Based on the analysis of a failed refrigerator drawer and handle systems, we demonstrated our new reliability design method. The new method uses ALT; the new concept of product life, $L_{B}$; and sample size, as a novel means of determining proper design parameters [7-14]. 


\subsection{Targeting the refrigerator $B_{X}$ life and failure rate $\lambda$}

The multi-unit refrigerator used as a case study for this method consists of a compressor, a drawer, a door, a cabinet, and other units. For the drawer, the $B_{1}$ life of the new design is targeted to be over 10 years with a yearly failure rate of $0.1 \%$. The entire refrigerator's $B \times$ life can be obtained by summing up the failure rates of each refrigerator unit. The refrigerator's $B_{12}$ life with the new design is targeted to be over 10 years with a yearly failure rate of $1.2 \%$ (Table 1) [19].

\begin{tabular}{|c|c|c|c|c|c|c|c|c|c|}
\hline No & Units & $\begin{array}{l}\text { Market L } \\
\text { Failure Rate }\end{array}$ & $\begin{array}{l}\text { Bata } \\
\text { Life }\end{array}$ & Design & Conversion & $\begin{array}{c}\text { Expected } \\
\text { Failure Rate }\end{array}$ & $\begin{array}{l}\text { Target } \\
B x \text { Life }\end{array}$ & $B x$ Life & Based $B x$ \\
\hline 1 & Compressor & 0.34 & 5.3 & New & $\mathrm{x} 5$ & 1.70 & 0.10 & 10 & B1.0 \\
\hline 2 & Door & 0.35 & 5.1 & Given & $\mathrm{x} 1$ & 0.35 & 0.15 & 10 & B1.5 \\
\hline 3 & Cabinet & 0.25 & 4.8 & Modified & $\mathrm{x} 2$ & 0.50 & 0.10 & 10 & B1.0 \\
\hline 4 & Drawer & 0.20 & 6.0 & New & $x 2$ & 0.40 & 0.10 & 10 & B1.0 \\
\hline 5 & Heat exchanger & 0.15 & 8.0 & Given & $\mathrm{x} 1$ & 0.15 & 0.10 & 10 & B1.0 \\
\hline 6 & etc & 0.50 & 12.0 & Given & $\mathrm{x} 1$ & 0.50 & 0.50 & 10 & B6.0 \\
\hline Sum & R-Set & 1.79 & 7.4 & - & - & 3.60 & 1.10 & 10 & B12.0 \\
\hline
\end{tabular}

Table 1. Total parametric ALT plan of refrigerator

\subsection{Analysis of the problems identified in field samples (loads analysis)}

In the field, certain components in these refrigerators had been failing or making noise, causing consumers to replace their refrigerators. Data from the failed products in the field showed how common used the refrigerators under common usage conditions. Refrigerator reliability problems in the field occur when the parts cannot endure repetitive stresses due to internal or external forces over a specified period of time. The energy flow in a refrigerator (or other mechanical) system can generally be expressed as efforts and flows (Table 2) [15]. Thus, the stresses come from the efforts.

\begin{tabular}{ccc}
\hline $\begin{array}{c}\text { Refrigerator Units } \\
\text { (or Parts) }\end{array}$ & Effort, $\boldsymbol{e}(t)$ & Flow, $f(t)$ \\
\hline $\begin{array}{c}\text { Mechanical translation } \\
\text { (draws, dispenser lever) }\end{array}$ & Force component, $F(t)$ & Velocity component, $V(t)$ \\
\hline $\begin{array}{c}\text { Mechanical rotation } \\
\text { (door, cooling fan) }\end{array}$ & Torque component, $\tau(t)$ & Angular velocity component, $V(t)$ \\
\hline Compressor & Pressure difference, $\Delta P(t)$ & Volume flow rate, $Q(t)$ \\
\hline $\begin{array}{c}\text { Electric } \\
(\mathrm{PCB}, \text { condenser })\end{array}$ & Voltage, $V(t)$ & Current, $i(t)$ \\
\hline
\end{tabular}

Table 2. Effort and flow in the multi-port system

For a mechanical system, the time-to-failure approach employs a generalized life model (LS model) [16], such as: 


$$
T_{f}=A(S)^{-n} \exp \frac{E_{a}}{k T}=A(e)^{-n} \exp \frac{E_{a}}{k T}
$$

Repetitive stress can be expressed as the duty effect that carries the on/off cycles and shortens part life [17]. Under accelerated stress conditions, the acceleration factor (AF) can be described as:

$$
A F=\left(\frac{S_{1}}{S_{0}}\right)^{n}\left[\frac{E_{a}}{k}\left(\frac{1}{T_{0}}-\frac{1}{T_{1}}\right)\right]=\left(\frac{e_{1}}{e_{0}}\right)^{n}\left[\frac{E_{a}}{k}\left(\frac{1}{T_{0}}-\frac{1}{T_{1}}\right)\right]
$$

And $n$ can be determined by multiple testings with different stress levels.

\subsection{Parametric ALT with $B_{X}$ life and sample size}

Traditionally, the characteristic life is defined as:

$$
\eta^{\beta} \equiv \frac{\sum t_{i}^{\beta}}{r} \cong \frac{n \cdot h^{\beta}}{r}
$$

As the reliability of a product (or part) improves, failures of the product become less frequent in laboratory tests. Thus, it becomes more difficult to evaluate the characteristic life using Equation (4). The distribution of failed samples should follow the Poisson distribution for small samples [18]. For a $60 \%$ confidence level, the characteristic life can be redefined as

$$
\eta^{\beta} \cong \frac{1}{r+1} \cdot n \cdot h^{\beta}
$$

In order to introduce the $B x$ life in the Weibull distribution, the characteristic life can be modified as

$$
L_{B}^{\beta} \cong x \cdot \eta^{\beta}=\frac{x}{r+1} \cdot n \cdot h^{\beta}
$$

where $L_{B}=B X$ life and $x=0.01 X$, on the condition that $x \leq 0.2$.

$B X$ is the time by which $X \%$ of the drawer and handle system installed in a particular population of refrigerators will have failed. In order to assess the $B \times$ life with about a $60 \%$ confidence level, the number of test samples is derived in Eq. (7). That is,

$$
n \cong \frac{1}{x} \cdot(r+1) \cdot\left(\frac{1}{h^{*}}\right)^{\beta}
$$

with the condition that the durability target is defined as follows,

$$
h^{*}=(A F \cdot h) / L_{B} \geq 1
$$

Based on the customer usage conditions, the normal range of operating conditions and cycles of the product (or parts) are determined. Under the worst case, the objective number 
of cycles and the number of required test cycles can be obtained from Eq. (7). ALT equipment can then be conducted on the basis of load analysis. Using ALT we can find the missing or improper parameters in the design phase.

\subsection{Refrigerator unit $L B x$ life and failure rate, $\lambda$, with the improved designs}

The parameter design criterion of the newly designed samples can be more than the target life of $B x=10$ years. From the field data and from a sample under ALT with a corrective action plans, we can obtain the missing or improper parameters of parts and their levels in the design phase.

With the improved design parameters, we can derive the expected $L B x$ life of the final design samples using Equation (6).

$$
L_{B}^{\beta} \cong x \cdot \frac{n \cdot(h \cdot A F)^{\beta}}{r+1}
$$

Let $x=\lambda \cdot L_{B}$ in Equation (9). The failure rate of the final design samples is derived in Equation (10)

$$
\lambda \cong \frac{1}{L_{B}} \cdot(r+1) \cdot \frac{L_{B}^{\beta}}{n \cdot(h \cdot A F)^{\beta}}
$$

\section{Case study: Reliability design of a refrigerator drawer and handle system}

Figure 2 shows a refrigerator with the newly designed drawer and handle system and its parts. In the field, the refrigerator drawer and handle system had been failing, causing consumers to replace their refrigerators (Figure 3). The specific causes of failures of the refrigerator drawers during operation were repetitive stress and/or the consumer improper usage. Field data indicated that the damaged products had structural design flaws, including sharp corner angles and weak ribs that resulted in stress risers in high stress areas.

A consumer stores food in a refrigerator to have convenient access to fresh food. Putting food in the refrigerator drawer involves opening the drawer to store or takeout food, closing the drawer by force. Depending on the consumer usage conditions, the drawer and handle parts receive repetitive mechanical loads when the consumer opens and closes the drawer.

Figure 4 shows the functional design concept of the drawer and handle system. The stress due to the weight load of the food is concentrated on the handle and support slide rail of the drawer. Thus, the drawer must be designed to endure these repetitive stresses.

The force balance around the drawer and handle system cans be expressed as:

$$
F_{\text {draw }}=\mu W_{\text {load }}
$$




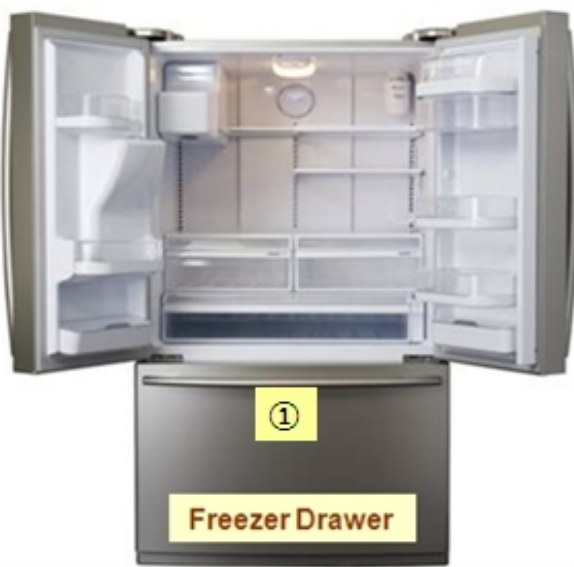

(a)

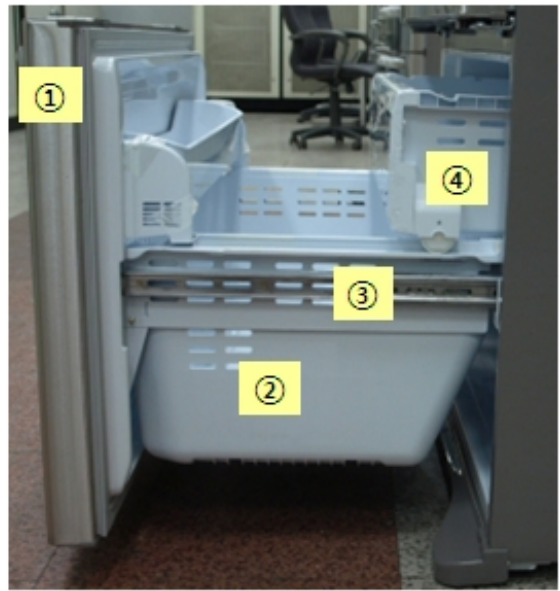

(b)

Figure 2. Refrigerator and drawer assembly. (a) French refrigerator (b) Mechanical parts of the drawer: handle (1), drawer (2), slide rail (3), and pocket box (4)

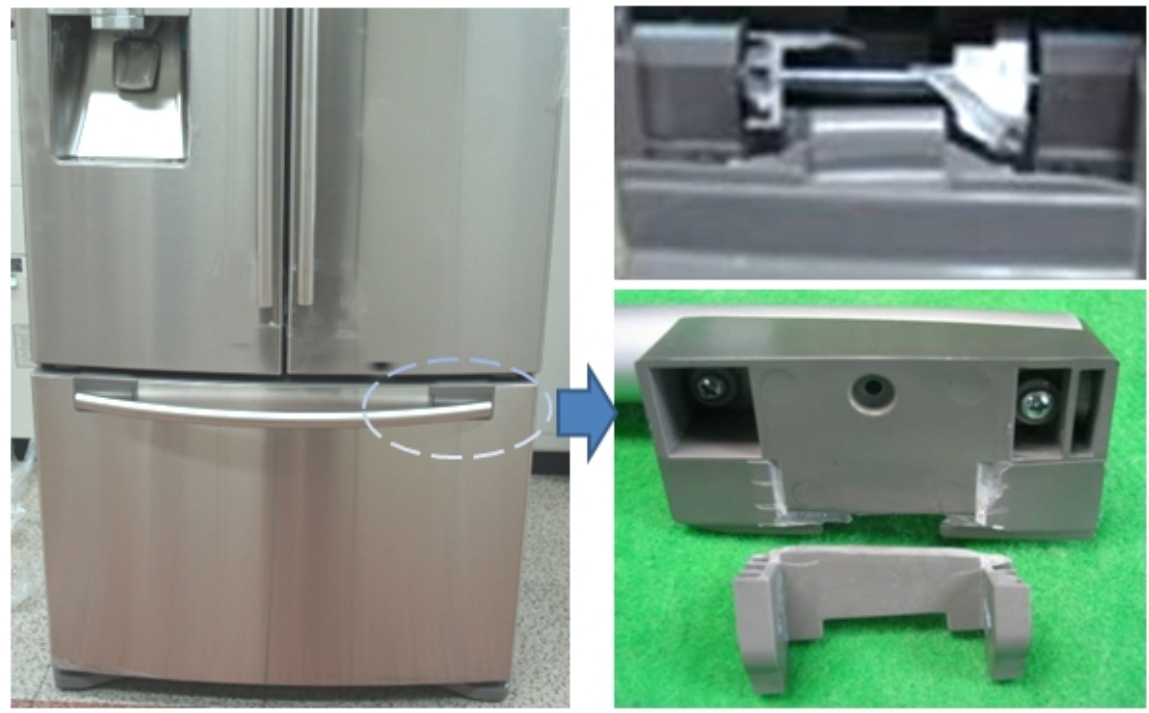

Figure 3. A damaged product after use 
Key Noise Parameters

N1: Customer usage \& load Conditions

N2: Environmental Conditions

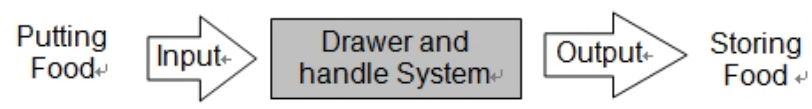

Key Control Parameters

$\mathrm{C} 1$ : Drawer and handle material \& size

(a) Parameter diagram of drawer and handle system

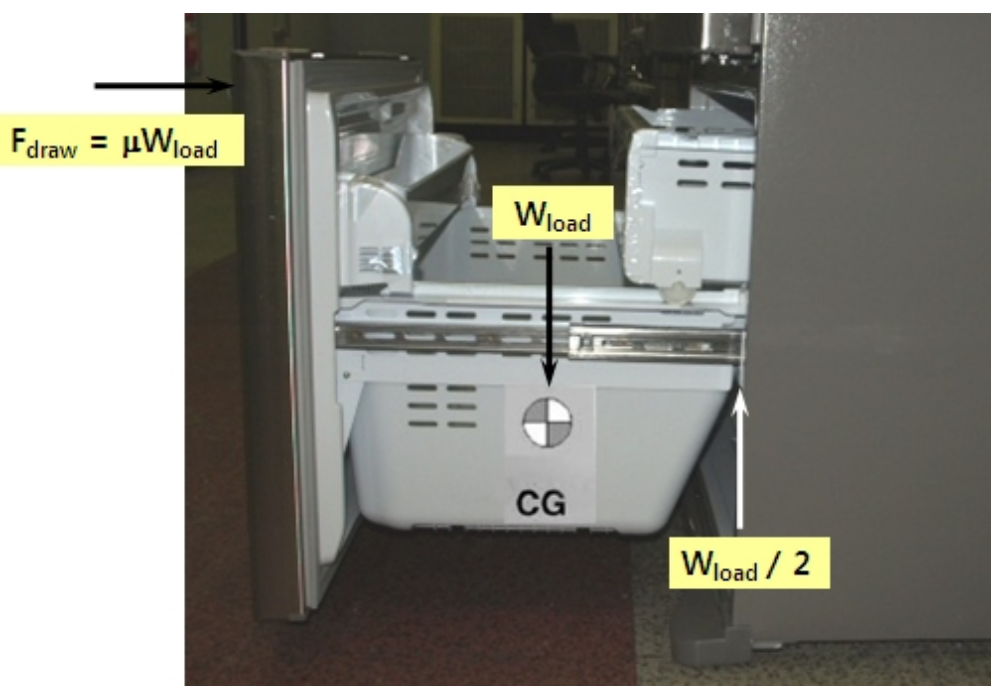

(b) Design concept of mechanical drawer and handle system

Figure 4. Functional design concept of the drawer and handle system

Because the stress of the drawer and handle system depends on the food weight, the lifestress model (LS model) can be modified as follows:

$$
T_{f}=A(S)^{-n}=A\left(F_{\text {draw }}\right)^{-n}=A\left(\mu W_{\text {load }}\right)^{-n}
$$

where $\mathrm{A}$ is constant. Thus, the acceleration factor $(A F)$ can be derived as

$$
A F=\left(\frac{S_{1}}{S_{0}}\right)^{n}=\left(\frac{F_{1}}{F_{0}}\right)^{2}=\left(\frac{\mu W_{1}}{\mu W_{0}}\right)^{2}=\left(\frac{W_{1}}{W_{0}}\right)^{2}
$$

\section{Laboratory experiments}

The normal ranges of the operating conditions for the drawer system and handle were 0 to $50^{\circ} \mathrm{C}$ ambient temperature, 0 to $85 \%$ relative humidity and 0.2 to $0.24 \mathrm{G}$ vibration. The normal 
number of operating cycles for one day was approximately 5; the worst case was 9. Under the worst case, the objective drawer open/close cycles for ten years would be 32,850 cycles (Table 3).

\begin{tabular}{ccccc}
\hline \multirow{2}{*}{ Item } & \multicolumn{4}{c}{ Number of operations (times) } \\
\cline { 2 - 5 } & \multicolumn{3}{c}{ 1 day } & \multicolumn{3}{c}{10 years } \\
\cline { 2 - 5 } & Normal & Worst & Normal & Worst \\
\hline Drawer & 5 & 9 & 18,250 & 32,850 \\
\hline
\end{tabular}

Table 3. Operating number of a drawer

For the worst case, the food weight force on the handle of the drawer was $0.34 \mathrm{kN}$. The applied food weight force for the ALT was $0.68 \mathrm{kN}$. With a quotient, $n$, of 2, the total $A F$ was approximately 4.0 using equation (13).

The parameter design criterion of the newly designed drawer can be more than the target life of $B_{1}=10$ years. Assuming the shape parameter $\beta$ was 2.0 and $x$ was 0.01 , the test cycles and test sample numbers calculated in Equation (7) were 67,000 cycles and 3 units, respectively. The ALT was designed to ensure a $B_{1}$ life of 10 years with about a $60 \%$ level of confidence that it would fail less than once during 67,000 cycles.
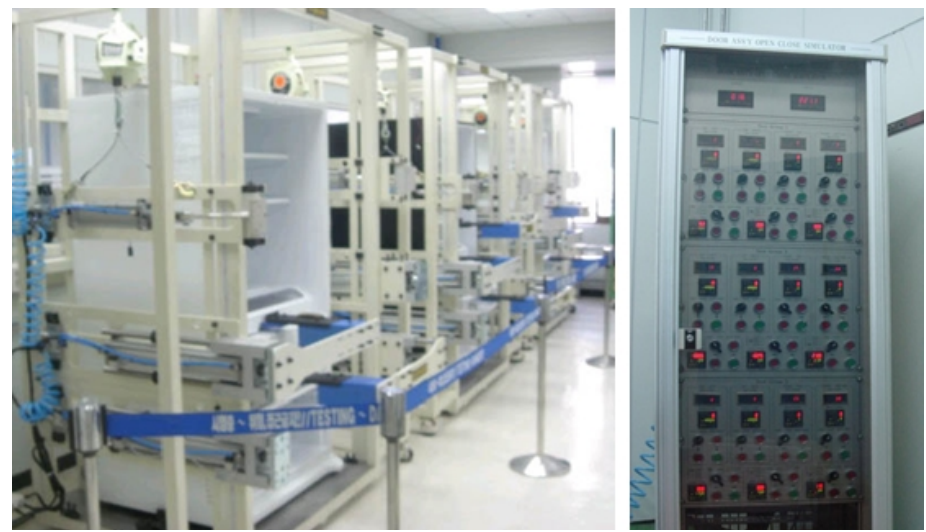

(a) ALT equipment and controller

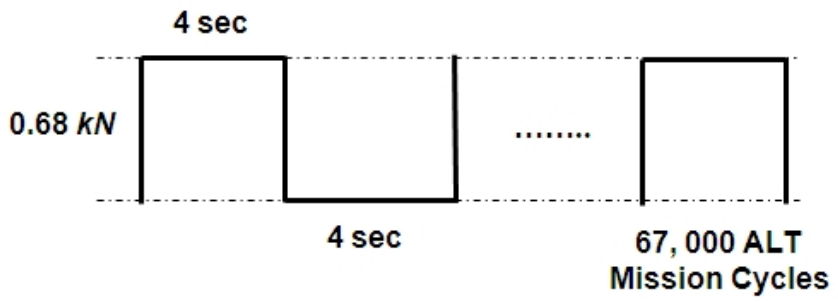

(b) Duty cycles of repetitive food weight force on the drawer

Figure 5. ALT equipment and duty cycles. 
Figure 5 shows ALT equipment and duty cycles for the repetitive food weight force, $F_{\text {draw }}$. For the ALT experiments, the control panel on top of the testing equipment started and stopped the drawer during the mission cycles. The food load, F, was controlled by the accelerated weight load in the drawer storage. When a button on the control panel was pushed, mechanical arms and hands pushed and pulled the drawer.

\section{Parametric ALTs with corrective action plans}

Figures 6(a) and 6(b) show the failed product from the field and the $1^{\text {st }}$ accelerated life testing, respectively. The failure sites in the field and the first ALT occurred at the drawer handle as a result of high concentrated stress. Figure 7 shows a graphical analysis of the ALT results and field data on a Weibull plot. For the shape parameter, the estimated value on the chart was 2.0. For the final design, the shape parameter was determined to be 3.1. These methodologies were valid for pinpointing the weak design responsible for failures in the field and $1^{\text {st }}$ ALT.
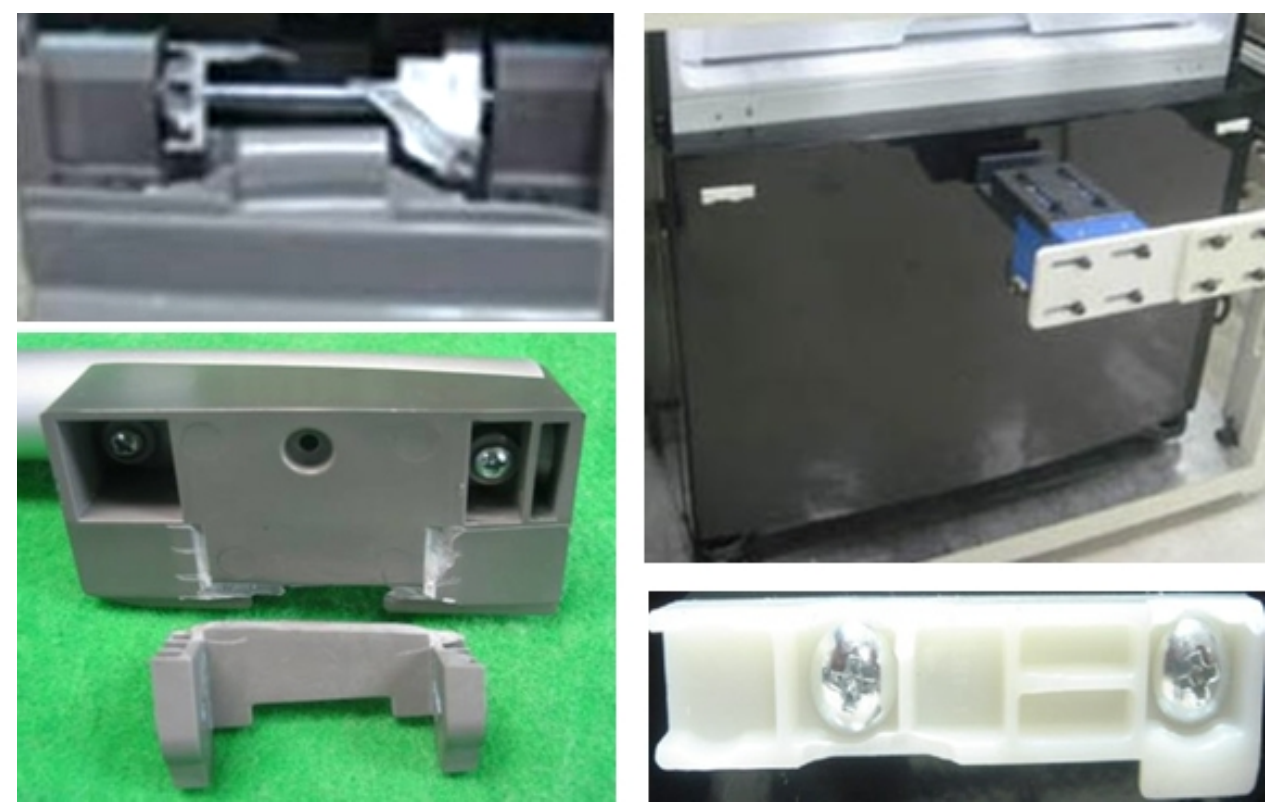

(a) Failed product in field

(b) Failed sample in first accelerated life testing

Figure 6. Failed products in field and first ALT 


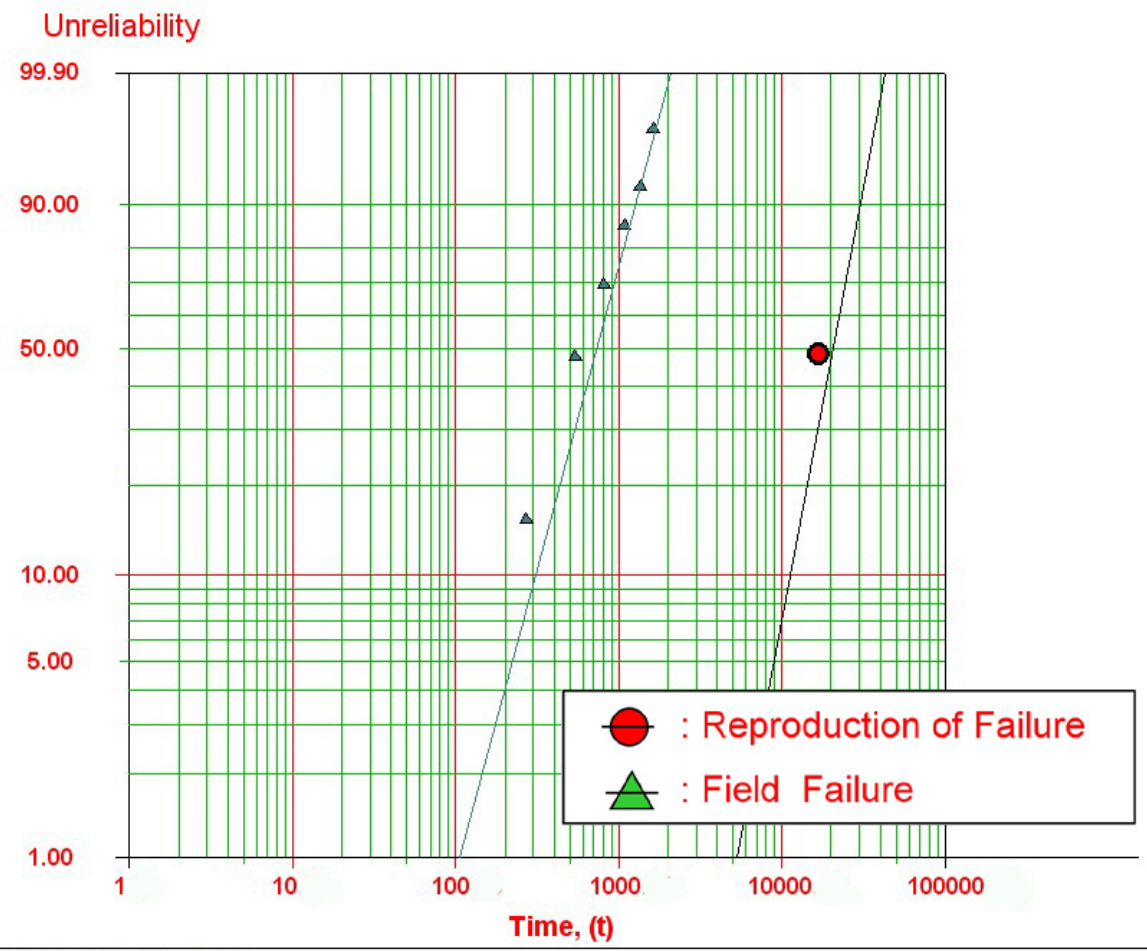

$\beta 1=3.1390, \eta 1=2.3083 \mathrm{E}+4$

$\beta 2=2.1933, \eta 2=862.3961$

Figure 7. Field data and results of $1^{\text {st }}$ ALT on Weibull chart.
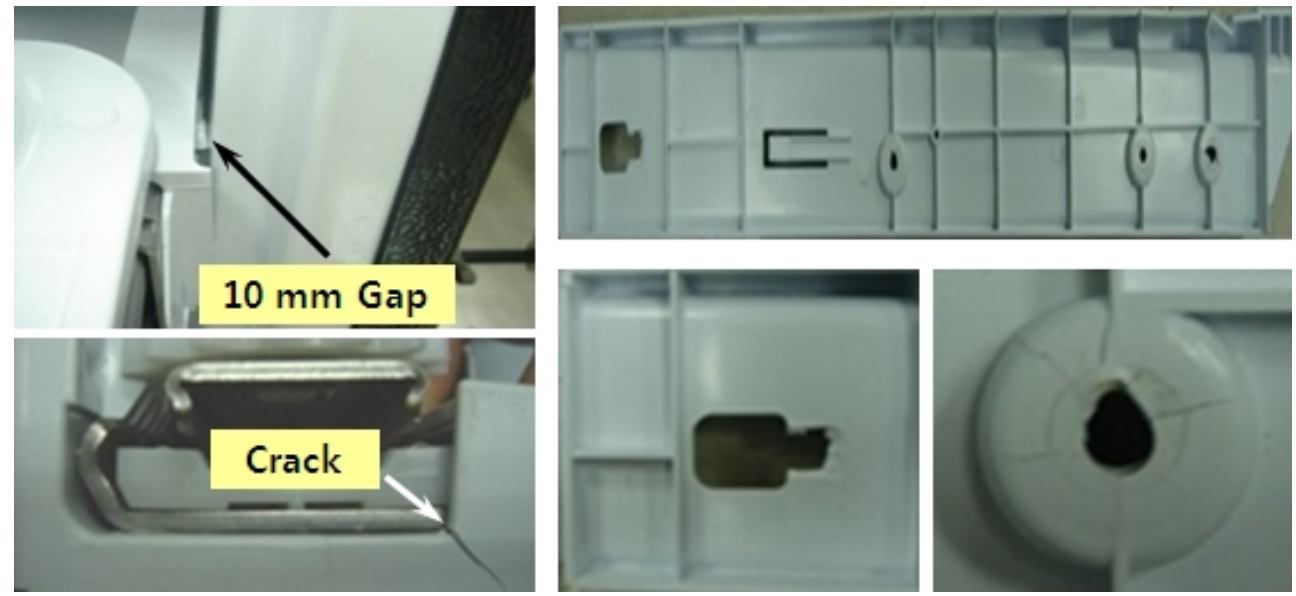

Figure 8. Failed slide rails in second ALT 
The fracture of the drawer in the first and second ALTs occurred in the handle and slide rails (Figure 6(b) and Figure 8). The missing or improper parameters of the handle and slide rails in the design phase are listed in Table 4 . These design flaws can result in a fracture when the repetitive food load is applied.

\begin{tabular}{ccccc}
\hline CTQ & & & Parameters & Unit \\
\hline \multirow{4}{*}{ Fracture } & KNP & N1 & Consumer food loading & $\mathrm{kN}$ \\
\cline { 3 - 5 } & & $\mathrm{C} 1$ & Reinforced handle width & - \\
\cline { 3 - 5 } & \multirow{2}{*}{ KCP } & Handle hooker width & - \\
\cline { 3 - 5 } & & $\mathrm{C} 3$ & Fastening screw number & - \\
\cline { 3 - 5 } & & $\mathrm{C} 4$ & Slide rail chamber & $\mathrm{mm}$ \\
\cline { 3 - 5 } & & $\mathrm{C} 5$ & Slide rail boss thickness & $\mathrm{mm}$ \\
\cline { 3 - 5 } & $\mathrm{C} 6$ & New added rib & - \\
\hline
\end{tabular}

Table 4. Vital parameters based on ALTs

To prevent the fracture problem and release the repetitive stresses, the handle and slide rails were redesigned. The corrective action plan for the design parameters included: (1) increasing the width of the reinforced handle, $\mathrm{C} 1$, from $90 \mathrm{~mm}$ to $122 \mathrm{~mm}$; (2) increasing the handle hooker size, $\mathrm{C} 2$, from $8 \mathrm{~mm}$ to $19 \mathrm{~mm}$; (3) increasing the rail fastening screw number, C3, from 1 to 2; (4) adding an inner chamber and plastic material, C4, from HIPS to ABS; (5) thickening the boss, C5, from $2.0 \mathrm{~mm}$ to $3.0 \mathrm{~mm}$; (6) adding a new support rib, C6 (Table 5).

The parameter design criterion of the newly designed samples was more than the target life, $B_{1}$, of ten years. The confirmed value, $\beta$, on the Weibull chart was 3.1. For the second ALT, the recalculated test cycles and sample size in Equation (7) were 32,000 and 3 units, respectively. In the third ALT, no problems were found with the drawer after 32,000 cycles and 65,000 cycles. We therefore concluded that the modified design parameters were effective.

Table 6 provides a summary of the ALT results. Figure 9 shows the results of the $1^{\text {st }}$ ALT and $3^{\text {rd }}$ ALT plotted in a Weibull chart. With the improved design parameters, the $B_{1}$ life of the samples in the third ALT was lengthened to more than 10.0 years. 


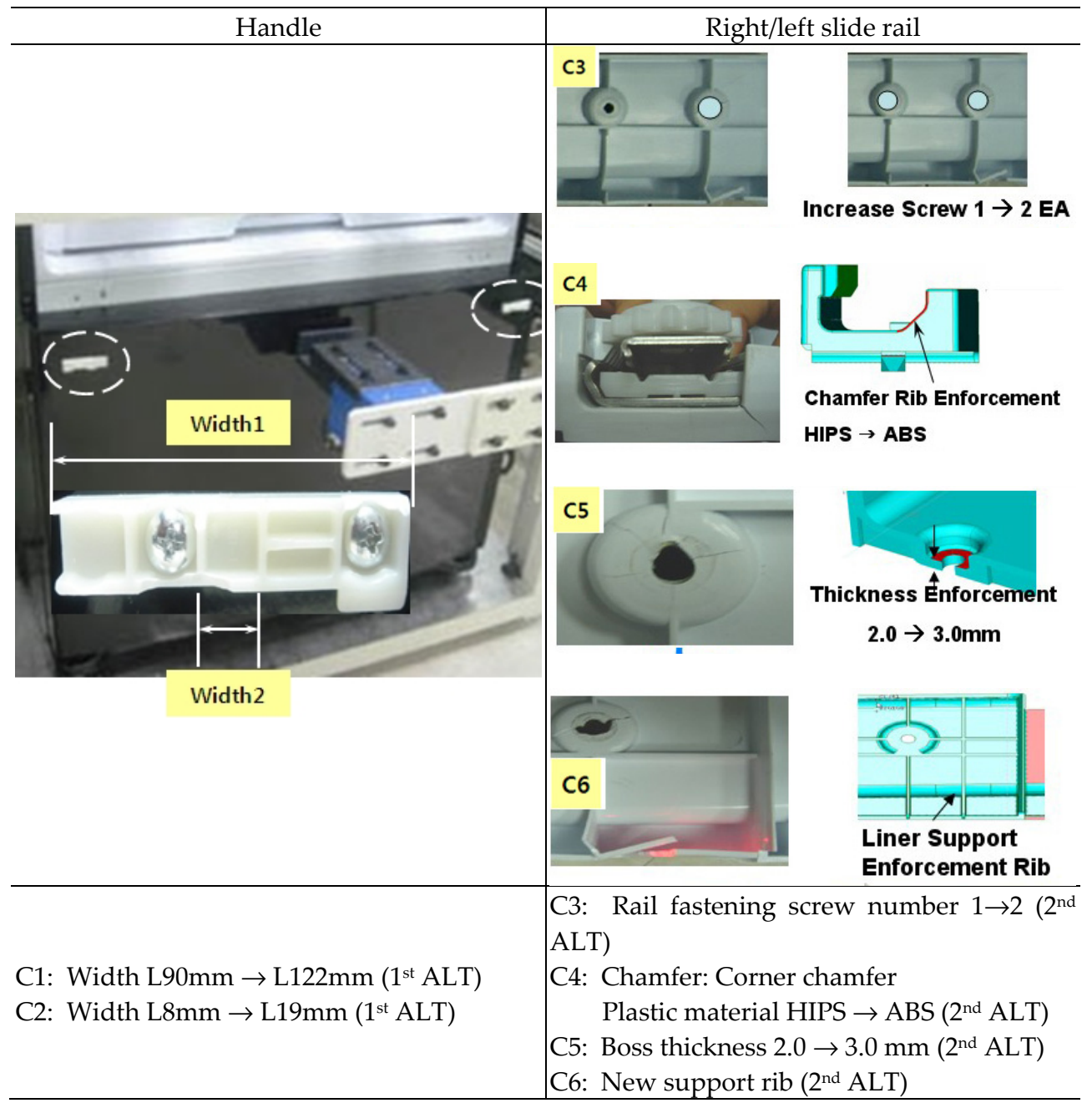

Table 5. Redesigned handle and right/left slide rail 


\section{Unreliability}

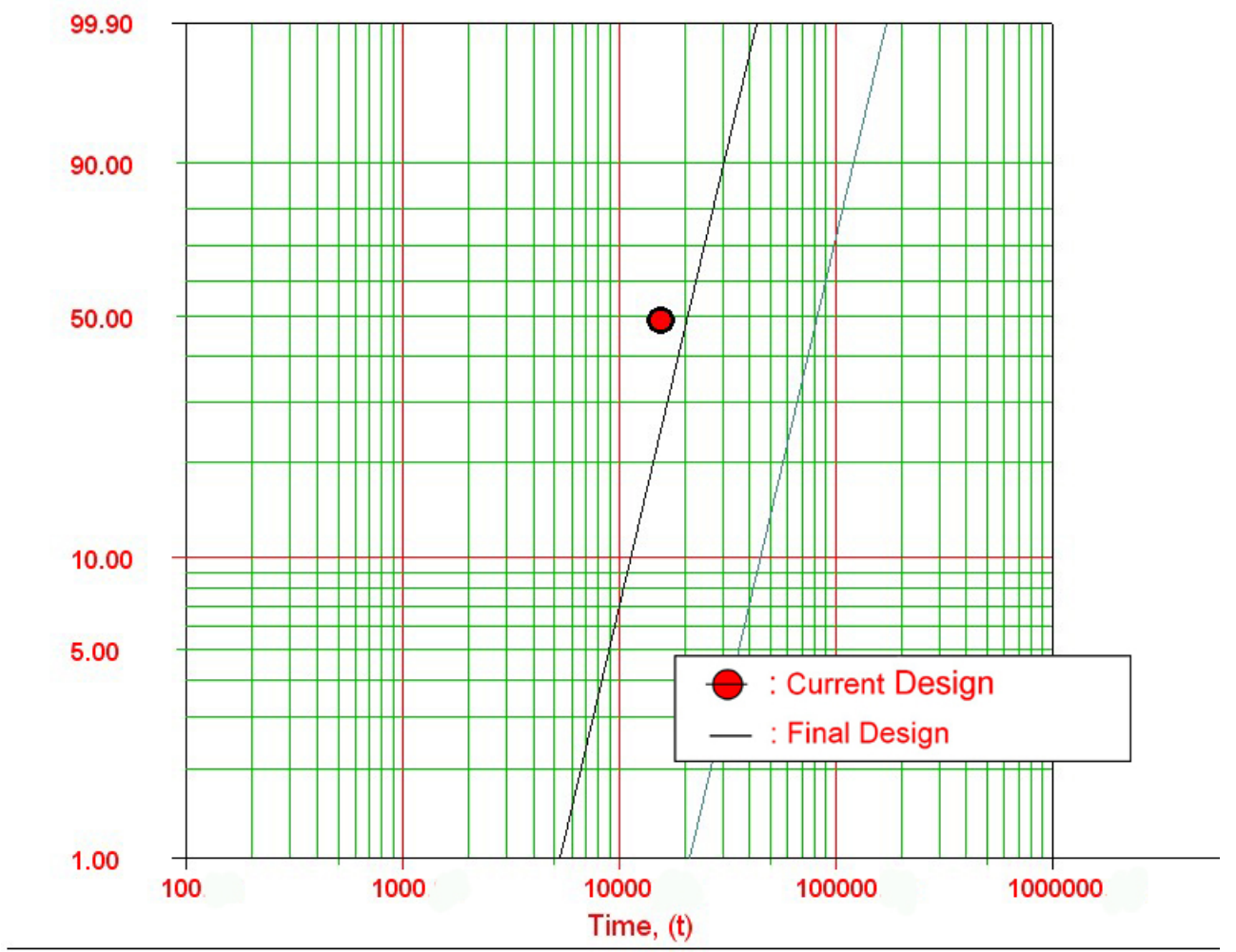

$\beta 1=3.1390, \eta 1=2.3083 \mathrm{E}+4$

$\beta 2=3.1100, \eta 2=9.2550 \mathrm{E}+4$

Figure 9. Results of $1^{\text {st }}$ ALT and $3^{\text {rd }}$ ALT plotted in Weibull chart 


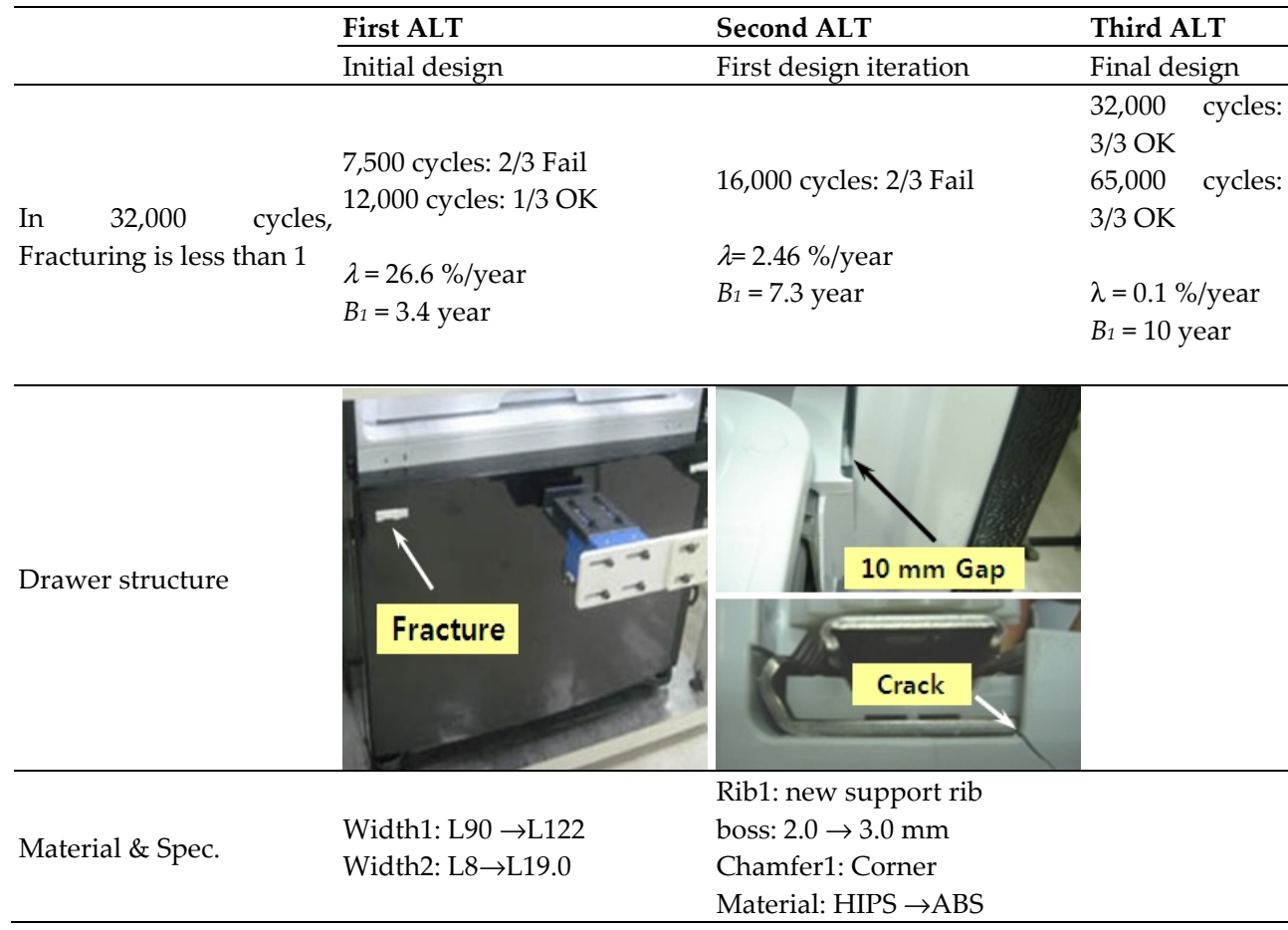

Table 6. Results of ALTs

\section{Conclusions}

We developed a new reliability design method based on a study of a defective refrigerator drawer and handle system that was failing under field use conditions. The failure modes and mechanisms for the drawer in the field and in the ALTs were identified. Important design parameters were studied and improvements were evaluated using ALTs.

Based on the products returned from the field and the results of the first ALT, we found that the handles were fracturing because of design flaws. The handle design was corrected by increasing the handle width. During the second ALT, the slide rails fractured because they did not have enough strength to endure the repetitive food storage loads. The slide rails were corrected by providing additional reinforced ribs, reinforced boss, and an inner chamber. As a result these modified design parameters, there were no problems in the third ALT. We therefore concluded that the values for the design parameters were effective to meet the life cycle requirements. The yearly failure rate and $B_{1}$ life of the redesigned drawer and handle system, based on the results of ALT, were under $0.1 \%$ and more than 10 years, respectively. The study of the missing or improper design parameters in the design phase, through the inspection of failed products in the field, load analysis, and ALTs was very effective in redesigning more reliable parts with significantly longer life. 
The case study focused on a mechanical structure consisting of several parts subjected to repetitive stresses under consumer usage conditions. The same principles developed for the new reliability design methodology could be applied to other mechanical systems, including construction equipment, automobile gear trains and engines, forklifts, washing machines, vacuum cleaners, and motor fan systems. We recommend that the missing or improper controllable design parameters on these systems also be studied for reliability design. These parameter studies would also include failure analysis, load analysis, and a tailored series of accelerated life tests. These methodologies could then predict part life quantitatively through accelerated factors and exact sample size.

\section{Nomenclature}

$A F \quad$ acceleration factor

$B x \quad$ durability index

C1 width of reinforced handle, $\mathrm{mm}$

C2 width of handle hooker, $\mathrm{mm}$

C3 back rib of slide rail

C4 screw boss height of slide rail, $\mathrm{mm}$

C5 inner chamber of slide rail

C6 material of slide rail

C7 screw number of slide number

e effort

eo effort under normal stress conditions

$e_{1} \quad$ effort under accelerated stress conditions

$E_{a} \quad$ activation energy

$f \quad$ flow

$F(t) \quad$ unreliability

Fdraw open/close force of the freezer drawer system, $k N$

$F_{1} \quad$ weight force under accelerated stress conditions, $k N$

Fo weight force under normal conditions, $k N$

$h \quad$ testing time (or cycles)

$h^{*} \quad$ non-dimensional testing cycles, $h^{*}=h / L_{B} \geq 1$

$i \quad$ current, $A$

$k \quad$ Boltzmann's constant, $8.62 \times 10^{-5} \mathrm{eV} / \mathrm{deg}$

KCP Key Control Parameter

KNP Key Noise Parameter

$L B \quad$ the target $B X$ life and $x=0.01 \mathrm{X}$, on the condition that $x \leq 0.2$

$n \quad$ the number of test samples

N1 consumer freezer door drawer open/close force, $k N$

$\triangle P \quad$ pressure difference, $M P a$

$r \quad$ failed numbers 
$R \quad$ reliability function

$S \quad$ stress

So mechanical stress under normal stress conditions

$S_{1} \quad$ mechanical stress under accelerated stress conditions

$t_{i} \quad$ test time for each sample

$T$ absolute temperature, $K$

$T_{1} \quad$ absolute temperature under accelerated stress conditions, $K$

$T_{0} \quad$ absolute temperature under normal stress conditions, $K$

$T_{f} \quad$ time to failure

$V \quad$ velocity, $\mathrm{m} / \mathrm{s}$

$V \quad$ voltage, volt

$W_{1} \quad$ food weight force under accelerated stress conditions, $k N$

$W_{0} \quad$ food weight force under normal stress conditions, $k N$

$W_{\text {load }}$ total food weight force in the freezer door drawer, $k N$

$X \quad$ accumulated failure rate, $\%$

$x \quad x=0.01 \cdot X$, on condition that $x \leq 0.2$.

Greek symbols

$\begin{array}{ll}\eta & \text { characteristic life } \\ \lambda & \text { failure rate } \\ \mu & \text { friction coefficient }\end{array}$

Superscripts

$\beta \quad$ shape parameter in a Weibull distribution

$n \quad$ stress dependence, $n=-\left[\frac{\partial \ln \left(T_{f}\right)}{\partial \ln (S)}\right]_{T}$

Subscripts

0 normal stress conditions

1 accelerated stress conditions

\section{Author details}

Seong-woo Woo, Jungwan Park, Jongyun Yoon and HongGyu Jeon

STX Institute of Technology, Korea

\section{References}

[1] Taguchi, G., 1978, Off-line and On-line Quality Control Systems, Proceedings of the International Conference on Quality Control, Tokyo, Japan. 
[2] Taguchi, G., Shih-Chung, T, 1992, Introduction to Quality Engineering: Bringing Quality Engineering Upstream, American Society of Mechanical Engineering, New York.

[3] Ashley, S., 1992, Applying Taguchi's Quality Engineering to Technology Development, Mechanical Engineering.

[4] Wilkins, J., 2000, Putting Taguchi Methods to Work to Solve Design Flaws, Quality Progress, 33(5), 55-59.

[5] Phadke, M., 1989, Quality Engineering Using Robust Design, Englewood Cliffs, NJ: Prentice Hall.

[6] Byrne, D., Taguchi, S., 1987, Taguchi Approach to Parameter Design, Quality Progress, 20(12), 19-26.

[7] Woo, S., Pecht, M., 2008, Failure Analysis and Redesign of a Helix Upper Dispenser, Engineering Failure Analysis, 15 (4), 642-653.

[8] Woo, S., O'Neal, D., Pecht, M., 2009, Improving the Reliability of a Water Dispenser Lever in a Refrigerator Subjected to Repetitive Stresses, Engineering Failure Analysis, 16 (5), 1597-1606.

[9] Woo, S., O’Neal, D., Pecht, M., 2009, Design of a Hinge Kit System in a Kimchi Refrigerator Receiving Repetitive Stresses, Engineering Failure Analysis, 16 (5), 16551665.

[10] Woo, S., Ryu, D., Pecht, M., 2009, Design Evaluation of a French Refrigerator Drawer System Subjected to Repeated Food Storage Loads, Engineering Failure Analysis, 16 (7), 2224-2234.

[11] Woo, S., O'Neal, D., Pecht, M., 2010, Failure Analysis and Redesign of the Evaporator Tubing in a Kimchi Refrigerator, Engineering Failure Analysis, 2010, 17(2), 369379.

[12] Woo, S., O'Neal, D., Pecht, M., 2010, Reliability design of a reciprocating compressor suction reed valve in a common refrigerator subjected to repetitive pressure loads, Engineering Failure Analysis, 2010, 17(4), 979-991.

[13] Woo, S., Pecht, M., O’Neal, D., 2009, Reliability Design and Case Study of a Refrigerator Compressor Subjected to Repetitive Loads, International Journal of Refrigeration, 32 (3), 478-486

[14] Woo S, O’Neal D, Pecht M. Reliability design of residential sized refrigerators subjected to repetitive random vibration loads during rail transport, Engineering Failure Analysis 2011, 18(5), 1322-1332.

[15] Karnopp, D., Margolis, D., Rosenberg, R., 2000, System Dynamics: Modeling and Simulation of Mechatronic Systems, third ed. John Wiley \& Sons, Inc, New York.

[16] McPherson, J., 1989, Accelerated Testing, Packaging, Electronic Materials Handbook, ASM International 1, 887-894.

[17] Ajiki, T., Sugimoto, M., Higuchi, H., 1979. A new cyclic biased THB power dissipating ICs. In: 17th Annual Proceedings Reliability Physics. pp. 118-126. 
[18] Ryu, D., Chang, S., 2005, Novel Concept for Reliability Technology, Microelectronics Reliability, 45 (3), 611-622.

[19] Ryu, D., 2012, Improving Reliability and Quality for Product Success, CRC Press 